\title{
INTERCOMUNICAÇÃO DO PORTUGUÊS COLOQUIAL E/OU NÃO PADRÃO E DO FRANCÊS PADRÃO EM AULA DE FRANCÊS LÍNGUA ESTRANGEIRA
}

\author{
Claudia Regina Minossi ROMBALDI* \\ Isabella MOZZILLO**
}

- RESUMO: Neste artigo, relacionam-se aspectos em variação no português àqueles cristalizados pela gramática no francês, com o objetivo de se estabelecerem intercomunicações entre produções que se assemelham no português coloquial e/ou não padrão e no francês padrão, partindo-se da hipótese segundo a qual atividades intercomunicativas de explicitação, entre tais particularidades, nas duas línguas, são capazes de gerar melhor proficiência na LE. Essa hipótese consubstancia-se em trabalhos como, por exemplo, os de Miranda de Paulo (2017), Candelier (2016) e Bagno (1999). A metodologia consiste em aulas expositivas e dialogadas, cujo foco incide em estimular os alunos a contrastarem e a inter-relacionarem atividades que contextualizem palavras ou expressões no francês padrão que se organizam de maneira semelhante à variação no português. Os resultados mostram que os sujeitos, além de terem contrastado as duas variedades, nas línguas em contato no estudo, também transpuseram estruturas de uma variedade a outra, adequando-as ao padrão do francês.

- PALAVRAS-CHAVE: didática integrada; português língua materna; francês língua estrangeira; francês padrão; português coloquial e/ou não padrão.

\section{Introdução}

Abordar aspectos em variação no português brasileiro, doravante português, àqueles que ocorrem categoricamente no francês podem suscitar comparações valiosas no âmbito do ensino e da aprendizagem, tanto da Língua Estrangeira (LE), quanto da Língua Materna (LM). Algumas produções consolidadas no francês tendem a se organizar de maneira semelhante à variação no português. É o caso, por exemplo, da lateral palatal $[\lambda]$, da neutralização do plural, do apagamento do /R/ final de infinitivos regulares, do apagamento do $/ \mathrm{m} /$ final de substantivos terminados por $/ \mathrm{eN} /$ das estruturas /aw/ produzidas como [o] e da regularidade do paradigma verbal.

\footnotetext{
Instituto Federal de Educação, Ciência e Tecnologia Sul-rio-grandense (IFSul). Câmpus Pelotas-Visconde da Graça (CaVG). Pelotas - RS - Brasil. professoraclaudiarombaldi@gmail.com. ORCID: 0000-0003-3405-1378.

** Universidade Federal de Pelotas (UFPel). Centro de Letras e Comunicação (CLC). Pelotas - RS - Brasil. isabellamozzillo@gmail.com. ORCID: 0000-0001-8445-9174.
} 
Trazer tais concepções para a sala de aula de Francês Língua Estrangeira (FLE), dentro de uma perspectiva de integração linguística, que promova o contraste entre as duas línguas - francês e português ${ }^{1}$-, embora em variedades distintas, pode trazer adjacente a oportunidade de facilitar a proficiência na LE. Destarte, tomando-se por base estudos que defendem a integração entre as línguas, em especial os que demonstram a possibilidade de trabalhar uma didática integrada, a presente proposta visa, em sala de aula de FLE, estabelecer intercomunicações entre produções que se assemelham no português coloquial ${ }^{2}$ e/ou não padrão e no francês padrão. Parte-se da hipótese de que atividades intercomunicativas de explicitação entre tais fenômenos são capazes de gerar melhor proficiência na LE, neste caso específico, do francês.

O texto está estruturado em cinco seções da seguinte forma. A primeira, concernente à parte introdutória, traz um breve relato quanto ao tema e ao objetivo. A segunda aborda o porquê de se fortalecer a integração do português coloquial e/ou não padrão em aulas de FLE, bem como as possíveis inter-relações entre as línguas, nas variedades na oralidade e na escrita, com base na literatura adotada para dar suporte ao estudo. A terceira descreve os procedimentos metodológicos empregados. Os resultados da pesquisa, juntamente com a descrição e a interpretação dos dados, são apresentados posteriormente. Por fim, as conclusões são expressas.

\section{Por que fortalecer a integração do português coloquial e/ou não padrão em aulas de FLE?}

No propósito de aliar, alargar, transferir saberes e valer-se, em sala de aula de LE, das experiências linguísticas que os alunos já têm, abordagens que defendem a integração linguística vêm ganhando cada vez mais eco. Segundo perspectivas que defendem esse viés, como as de Candelier (2016), Castellotti (2001, 2014), Moore (2008), Dahlet (2008), Chiss (2013), Miranda de Paulo (2017) e Degache e Garbarino (2017), por exemplo, ao se considerar o trabalho intercomunicativo, tem-se a possibilidade de se obterem como produtos decorrentes "reflexões linguísticas profícuas e desenvolvimento do espírito crítico" (DOGLIANI, 2008c, p. 5).

No tocante às línguas colocadas em contato neste artigo, o francês e o português, Dogliani (2008a) e Mozzillo (2006), ao correlacionarem determinadas variedades do português a estruturas semelhantes no francês, demonstrando processos parecidos nas duas línguas, através de comparações entre tendências, ora desprovidas de prestígio no português, que se manifestam categoricamente no francês padrão, afirmam haver como resultados aspectos como a transferência de saberes de uma língua a outra, bem como

\footnotetext{
A escolha das duas línguas românicas para o desenvolvimento da presente proposta justifica-se devido ao fato de a pesquisadora ser professora bivalente de PLM e de FLE em uma escola pública Federal da cidade de Pelotas, Rio Grande do Sul, Brasil, e ministrar, simultaneamente, as duas línguas para o Ensino Médio.

2 Adota-se o termo português coloquial e/ou não padrão na acepção de Bagno (1999, p. 15-16), levando-se em consideração o "alto grau de diversidade e de variabilidade".
} 
a possibilidade de dirimir preconceitos linguísticos. Oliveira (2008, p. 20) acrescenta ainda a oportunidade de se poder "valorizar a língua estrangeira e o próprio estrangeiro (o outro)". Considerações também apontadas por Bagno (1999) e por Bortoni-Ricardo (2005), sobretudo no que concerne à possibilidade de fazer da sala de aula um ambiente propício para se desmistificarem preconceitos e prejulgamentos linguísticos.

Partindo-se das aproximações linguísticas supracitadas, que podem advir de um trabalho intercomunicativo entre o português coloquial e/ou não padrão e o francês padrão em aulas de LE, explicitar e sobrepor vocábulos e expressões do português em variação sociolinguística, que fazem parte do cotidiano dos falantes, e que, por ocasiões, são desprovidas de prestígio social, àqueles, já consolidados no francês, tende a levar à compreensão de que algumas formas no português, além de se realizarem de maneira idêntica, já se encontram firmadas no francês pela gramática - o que virá a fortalecer as conexões entre as línguas e a auxiliar nas transferências. Semelhantemente a uma via de mão dupla, mutuamente, uma língua poderá ajudar a outra, em uma espécie de retroalimentação linguística.

No tocante à noção de transferência linguística, abordada no parágrafo precedente, Escudé e Calvo del Olmo (2019) explicam que essa ideia é central no processo de aquisição de uma nova língua, porque a noção de "transfert"3 será aquela que irá facilitar a realização de uma atividade em uma determinada situação, por meio de uma circunstância similar, porém previamente adquirida. Segundo os autores, é o incentivo às transferências linguísticas e ao estabelecimento de conexões entre línguas, que irá permitir aos aprendizes experimentarem e construírem por si mesmos a arquitetura da nova língua.

À vista disso, oportunizar a intercomunicação linguística e o aproveitamento das experiências em língua, neste caso especialmente da LM, na construção de novos conhecimentos e no desenvolvimento de novas competências, faz da sala de aula de LE um ambiente propício à reflexão e à construção de pontes ${ }^{4}$, bem como um ambiente de discussão intelectual e cultural frutuoso, um lugar privilegiado para discussão, reflexão, comparação e transferência de conhecimentos advindos das aproximações experimentadas (MIRANDA DE PAULO, 2017; CANDELIER, 2016). Responde-se, assim, à pergunta-título da seção Por que fortalecer a integração do português coloquial e/ou não padrão em aulas de FLE?

\section{Possíveis inter-relações do português coloquial e/ou não padrão e do francês padrão: interfaces entre as variedades na oralidade e na escrita}

Considerando-se o português e o francês, nas variedades tratadas neste estudo, na oralidade e na escrita, algumas intercomunicações que podem emergir decorrentes

\footnotetext{
Escudé e Calvo del Olmo (2019, p. 63) denominam "estratégia de tranferência".

4 Termo presente em vários momentos da obra de Escudé e Calvo del Olmo (2019), como por exemplo, nas páginas 63 e 109 .
} 
da aproximação linguística, no âmbito da integração do português coloquial e/ou não padrão em salas de aula de FLE, serão apresentadas na sequência ${ }^{5}$.

\section{(i) Neutralização do plural}

A perda da marcação do plural no português coloquial e/ou não padrão reproduz uma característica do francês padrão, em que se escreve o -s, mas se deixa de pronunciá-lo. Assim, o plural, no francês, é neutralizado, tal como ocorre no português coloquial e/ou não padrão - "mes amis riches" [mezamisiiðə] no francês e "meus amigo rico" [mewzamiguriku] no português coloquial e/ou não padrão. Observa-se que a neutralização do plural no português pode ocorrer tanto em variedades desprestigiadas, quanto nas de maior prestígio, "as criança" [askriẽse], por exemplo, entretanto no francês é a única possibilidade de ocorrência "les enfants" [lezãfã].

\section{(ii) Variação da lateral palatal $[\lambda]$}

No caso da pronúncia da lateral palatal $[\lambda]$, no francês padrão acontece de forma semelhante ao que está em variação no português, em certos vocábulos, em variedades não prestigiadas. Na língua francesa, tem-se -11 no registro escrito, produzido no registro falado como uma vogal arredondada, semifrontal e semifechada $[\kappa]$. Assim, registros falados no francês padrão como em [famij] famille, [fij] fille, [эьEj] oreille, por exemplo, remetem à [famije] famia (família), [fije] fia (filha), [oreje] oreia (orelha) em certos registros falados no português coloquial e/ou não padrão, em situações análogas, porém de menor prestígio.

\section{(iii) Apagamento do $/ \mathrm{R} /$ de infinitivos regulares}

Quanto aos verbos no infinitivo, em francês, os de maior número, os do primeiro grupo, terminados em -er não têm o /R/ pronunciado: [ale] para “aller", [вәgaьde] para "regarder". O mesmo fenômeno ocorre em variedades coloquiais e/ou não padrão do português, tanto de menor como nas de maior prestígio, em todos os infinitivos das três terminações verbais: [ama], [le], [vi] para amar, ler e vir, respectivamente no registro escrito.

\section{(iv) Estruturas /aw/ pronunciadas [o]}

No português coloquial e/ou não padrão, em certas variedades desprestigiadas, o ditongo /aw/ como em "aumentar" e "autoridade", por exemplo, é pronunciado como [o] - [omẽnta] e [otoridadzi]. No francês padrão uma das distribuições gráficas para o

\footnotetext{
5 Os exemplos apresentados fundamentam-se, mormente, em Bagno (1999), Bortoni-Ricardo (2004, 2005, 2014), Dogliani (2008a) e Mozzillo (2006).
} 
fone [o] é/aw/. Desta forma, palavras como "augmenter" e "autorité" são pronunciadas respectivamente [ogmãte], [отьвite], semelhantemente às estruturas coloquiais e/ou não padrão em variedades de menor prestígio no português.

(v) Apagamento do $/ \mathrm{m} /$ de substantivos terminados por $/ \mathrm{eN} /$

Em algumas variedades coloquiais e/ou não padrão do português, palavras como viagem, garagem e passagem podem ser pronunciadas, respectivamente, [viazi], [garazi] e [pasazi]. O mesmo ocorre no francês padrão com palavras como voyage [vwajazə], garage [gаказə] e passage [раsazə]. No português coloquial e/ou não padrão esta particularidade pode ser observada, tanto em variedades de menor, como nas de maior prestígio sociolinguístico, no francês, entretanto, é a única possibilidade de produção.

\section{(vi) Regularidade do paradigma verbal}

No português aparecem várias pessoas em concordância verbal na escrita (eu falo, tu falas, ele/ela fala, nós falamos, vós falais, vocês falam, eles/elas falam). Em situações de coloquialidade e/ou não padrão, de menor prestígio, aparecem apenas duas (eu falo [falu], tu/ele/ela/a gente/ você/nós/eles/elas/vocês - fala [fale]. Semelhantemente, o francês tem várias pessoas em concordância verbal na escrita (je parle, tu parles, Il/elle parle, nous parlons, vous parlez, ils/elles parlent), porém, somente três na produção (je, tu, Il/elle, on, ils/elles [равl], nous [равlõ], vous [равle]), com a possibilidade de serem apenas duas ([равl], [равle]) se "on parle" substituir "nous parlons". O Quadro 1, exibido a seguir, sistematiza a explicação supradita.

Quadro 1 - A regularidade do paradigma verbal

\begin{tabular}{|c|c|c|c|}
\hline $\begin{array}{l}\text { Português } \\
\text { Escrito }\end{array}$ & $\begin{array}{l}\text { Português Coloquial } \\
\text { e/ou não Padrão na } \\
\text { oralidade desprestigiada }\end{array}$ & $\begin{array}{l}\text { Francês } \\
\text { Escrito }\end{array}$ & $\begin{array}{l}\text { Francês } \\
\text { Padrão na } \\
\text { oralidade }\end{array}$ \\
\hline $\begin{array}{l}\text { Eu falo } \\
\text { tu falas } \\
\text { ele(a)/você fala } \\
\text { nós falamos } \\
\text { vós falais } \\
\text { vocês falam } \\
\text { eles(as) falam }\end{array}$ & $\begin{array}{l}\text { eu falo } \\
\text { [falu] } \\
\text { Tu/ele(a)/você/nós/ a } \\
\text { gente/vocês/eles(as) } \\
\text { fala [fale] }\end{array}$ & $\begin{array}{l}\text { je parle } \\
\text { tu parles } \\
\text { il/elle parle } \\
\text { nous parlons } \\
\text { vous parlez } \\
\text { ils/elles parlent }\end{array}$ & $\begin{array}{l}\text { je/tu/ il/ elle/ils/ } \\
\text { elles/on } \\
\text { [равl] } \\
\text { nous } \\
\text { [равlб̃] } \\
\text { vous } \\
\text { [равle] }\end{array}$ \\
\hline
\end{tabular}

Fonte: Elaboração própria.

De acordo com o Quadro 1 pode-se verificar que os verbos no registro falado do francês não constituem regra variável, mas categórica, enquanto que no português espelham, em alguns casos, a variação de menor prestígio sociolinguístico. 


\section{Procedimentos Metodológicos}

Os sujeitos que produziram os dados analisados neste estudo, à época da coleta, cursavam regularmente uma disciplina de FLE no Ensino Médio, como disciplina optativa - Língua Estrangeira III (Francês Básico I) em uma escola pública federal de ensino técnico e tecnológico, localizada no sul do estado do Rio Grande do Sul Brasil $^{6}$. A cada sujeito participante foi atribuído um número, com a finalidade de serem resguardados o sigilo e o anonimato quanto à sua identificação. A numeração também teve por fim facilitar o tratamento com os dados.

O corpus é composto por dados oriundos de três procedimentos de coleta, a saber:

1. explicitações dos fenômenos de intercomunicação entre as produções que ocorrem de maneira semelhante no francês padrão e no português coloquial e/ou não padrão;

2. gravações em áudios e vídeos das produções advindas da explicitação, posteriormente feitas as devidas degravações; e

3. anotações das reações e dos depoimentos dos sujeitos, frente às atividades de explicitações de fenômenos que acontecem categoricamente nas duas línguas, nas variedades distintas.

No conjunto de dados obtidos, foram selecionados intencionalmente, apenas aqueles que contemplassem os fenômenos analisados na pesquisa, ou seja, os que permitissem possibilidades de interpretação de intercomunicações entre o português coloquial e/ou não padrão e o francês padrão.

\section{Resultados}

No início de cada seção exibe-se um Quadro, contendo exemplos que serviram de apoio para as explicações das intercomunicações pretendidas. Em seguida, os dados, consubstanciados pelos depoimentos dos sujeitos frente à ocorrência ao contexto estudado, são descritos e interpretados.

(i) Dados extraídos da explicitação sobre a neutralização do plural

O Quadro 2 ilustra exemplos relativos à forma como o português coloquial e/ou não padrão na oralidade prestigiada e desprestigiada e na escrita, bem como o francês padrão na oralidade e na escrita, procedem quanto à neutralização do plural.

\footnotetext{
6 Os procedimentos de coleta, bem como os termos de consentimento encontram-se devidamente registrados na Plataforma Brasil.
} 
Quadro 2 - Exemplos concernentes à neutralização do plural no português coloquial e/ou não padrão e no francês padrão.

\begin{tabular}{|l|l|l|l|l|l|}
\hline \multicolumn{2}{|c|}{ Ocorrência } & \multicolumn{1}{|c|}{$\begin{array}{c}\text { Português } \\
\text { Escrita }\end{array}$} & $\begin{array}{l}\text { Português Coloquial e/ou } \\
\text { não Padrão na oralidade } \\
\text { prestigiada/desprestigiada }\end{array}$ & \multicolumn{1}{|c|}{$\begin{array}{c}\text { Francês } \\
\text { Escrita }\end{array}$} & $\begin{array}{c}\text { Francês } \\
\text { padrão na } \\
\text { oralidade }\end{array}$ \\
\hline $\begin{array}{l}\text { Neutralização } \\
\text { do plural }\end{array}$ & 1. & $\begin{array}{l}\text { Meus amigos } \\
\text { ricos }\end{array}$ & [mewzamiguriku] & $\begin{array}{l}\text { Mes amis } \\
\text { riches }\end{array}$ & [mezamíij] \\
\cline { 2 - 6 } & As crianças & [askriẽse] & Les enfants & [lezãfã] \\
\hline
\end{tabular}

Fonte: Elaboração própria.

Por intermédio do Quadro 2 (Fig. 2) é possível visualizar que a perda da marcação do plural, no registro falado do português coloquial e/ou não padrão, reproduz uma característica que o francês expressa desde o século XII, ou seja, o fato de se escrever o -s, mas de deixar de pronunciá-lo (ESCUDÉ; CALVO DEL OLMO, 2019). Em registros falados da língua francesa, em casos como, por exemplo, le poisson/les poissons [løpwas̃̃] é difícil distinguir o singular do plural na oralidade, somente por intermédio do artigo, pois ambas as formas, emergem foneticamente como [lopwas̃̃] (ESCUDÉ; CALVO DEL OLMO (2019).

Embora o português coloquial e/ou não padrão, iguala-se ao francês padrão, tanto na oralidade como na escrita, indicando o plural apenas no determinante, não é comum que os estudantes estabeleçam, por si só, diálogos entre esse fenômeno idêntico nas duas línguas. Assim, um simples chamado do professor para a visualização de que a neutralização do plural, na língua francesa, trata-se de um fenômeno histórico, assimilado nos registros falados e que ainda mantêm o conservadorismo histórico no registro escrito, permite que seja instaurado um ambiente propício à criticidade acerca da variação e da mudança linguística (DOGLIANI, 2008a).

Com base nessa premissa defendida por Dogliani (2008a), um simples olhar para a filologia da língua francesa, por parte do professor, pode funcionar como gatilho para a introdução de fatos históricos, que consolidaram a variação, e diálogos entre LE e LM. É o caso, por exemplo, da atividade, em que os alunos foram instados a ler a frase Madame Leblanc, vos petits-enfants, ça va?7, cuja produção exigia a neutralização do plural em enfants na palavra petits-enfants. Um dos sujeitos fez o comentário em 1a.

1a: Sujeito 1: Não lemos os "s" do plural, como na fala do português, mas os 't'temos que pronunciar?

O que se pode depreender acerca do comentário ilustrado em 1a é que o sujeito consegue estabelecer uma ligação entre o português coloquial e/ou não padrão e o francês padrão, ao neutralizar o plural em suas produções na LE, em seus registros

Disponível em: http://ayudafrances.blogspot.com/2014/01/conversacion-en-frances-sobre-la-familia.html. Acesso em: 19 abr. 2019. 
falados. Sua dúvida, no momento da leitura, parece recair sobre a marcação de outras consoantes, como no caso em 1a, que se refere à marcação ou não do [t] final na palavra petits-enfants. As observações da professora-pesquisadora parecem ter auxiliado na visualização e na compreensão do processo, bem como no entendimento de que a aplicação da neutralização do plural, cotidianamente, é parte integrante da LM.

(ii) Dados extraídos da explicitação sobre a variação da lateral palatal $[\lambda]$

O Quadro 3 demonstra exemplos relativos à forma como o português na escrita e o português coloquial e/ou não padrão na oralidade desprestigiada, bem como o francês padrão na oralidade e na escrita, procedem quanto à variação da lateral palatal $[\lambda]$.

Quadro 3 - Exemplos concernentes à variação da lateral palatal $[\lambda]$ no português coloquial e/ou não padrão e no francês padrão

\begin{tabular}{|c|c|c|c|c|c|}
\hline \multicolumn{2}{|c|}{ Ocorrência } & $\begin{array}{c}\text { Português } \\
\text { Escrita }\end{array}$ & $\begin{array}{l}\text { Português Coloquial } \\
\text { e/ou não Padrão } \\
\text { na oralidade } \\
\text { desprestigiada }\end{array}$ & $\begin{array}{c}\text { Francês } \\
\text { Escrita }\end{array}$ & $\begin{array}{l}\text { Francês } \\
\text { Padrão na } \\
\text { oralidade }\end{array}$ \\
\hline \multirow{3}{*}{$\begin{array}{l}\text { Variação da } \\
\text { lateral }[\lambda]\end{array}$} & 1. & Filha & [fje] & Fille & [fijə] \\
\hline & 2. & Família & [famije] & Famille & [famijə] \\
\hline & 3. & Orelha & [oreije] & Oreille & [эьЕіјə] \\
\hline
\end{tabular}

Fonte: Elaboração própria.

Observa-se que a vocalização da lateral palatal, exibida no Quadro 3, ocorre em processos idênticos nas duas línguas, porém em português é assimilável apenas por certos grupos sociais. Segundo Dogliani (2008a) é relevante, em casos análogos, a menção do fato de que a pronúncia vocalizada [y], altamente estigmatizada no português brasileiro, era a antiga pronúncia da lateral palatal $[\lambda]$ no francês, mas atualmente está consolidada, devido à evolução e à variação. Tomando-se como parâmetro esse axioma, procedeu-se à leitura de um fragmento da obra L'Amant de Marguerite Duras - Photo de famille ${ }^{8}$. Um dos sujeitos, ao ler o título do excerto, fez o comentário ilustrado em 2a, quando deparado à palavra famille.

2a: Sujeito 2: Famille/[famj] como [fa'mje] e [fje], né?

À época da realização da atividade, o sujeito hesitou sobre a pronúncia da palavra fille, na frase C'est.....garçon, c'est....fille (BADY; GREAVES; PETETIN, 1996) e perguntou o exibido em $2 \mathrm{~b}$.

8 Disponível em: https://pt.scribd.com/doc/208764104/L-Amant-Marguerite-Duras Acesso em: 28 ago. 2019. 
2b: Sujeito 2: Como é que eu leio aquela palavra? [fij]? Português informal ${ }^{9}$ de [fje], de filha?

Os dados em $2 \mathrm{a}$ e em $2 \mathrm{~b}$ sugerem que o sujeito consegue relacionar os fenômenos da variação da sua LM, relativos à pronúncia de menor prestígio da lateral palatal $[\lambda]$ àqueles da LE, consequentemente, prestigiados, o que parece ter surtido do detalhamento do processo, à ocasião da atividade de explicitação. Ainda, os depoimentos demonstrados em 2a e 2 b encontram, destarte, sustentação em Couto (2009), segundo o autor, a palavra "velho" é produzida como "véi" [vej] por uma grande parcela dos jovens brasileiros da atualidade, fato que aproxima produções em certos registros falados na LM, como "muié" [muje] e "paia", por exemplo, à produção na LE, nas variedades tratadas na discussão.

(iii) Dado extraído da explicitação sobre o apagamento do /R/ dos infinitivos regulares

Exemplos de como o português coloquial e/ou não padrão e o francês padrão procedem quanto ao apagamento do / $\mathrm{R} /$ final de infinitivos regulares, na escrita e em situações de oralidade de prestígio e não prestígio, estão apresentados no Quadro 4.

Quadro 4 - Exemplos concernentes ao apagamento de /R/ finais de infinitivos regulares no português coloquial e/ou não padrão e no francês padrão.

\begin{tabular}{|c|c|c|c|c|c|}
\hline \multicolumn{2}{|c|}{ Ocorrência } & $\begin{array}{l}\text { Português } \\
\text { Escrita }\end{array}$ & $\begin{array}{c}\text { Português Coloquial } \\
\text { e/ou não Padrão na } \\
\text { oralidade desprestigiada/ } \\
\text { desprestigiada }\end{array}$ & $\begin{array}{l}\text { Francês } \\
\text { Escrita }\end{array}$ & $\begin{array}{l}\text { Francês } \\
\text { Padrão na } \\
\text { oralidade }\end{array}$ \\
\hline \multirow{3}{*}{$\begin{array}{l}\text { Apagamento do } \\
\text { /R/ em infinitivos }\end{array}$} & 1. & Cantar & [kẽta] & chanter & 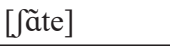 \\
\hline & 2. & Trabalhar & [traba $\Lambda \mathrm{a}]$ & travailler & [tRavaje] \\
\hline & 3. & Estudar & [istuda] & étudier & [etydje] \\
\hline
\end{tabular}

Fonte: Elaboração própria.

À semelhança das atividades de intercomunicação, já apresentadas, o Quadro 4 contém exemplos de infinitivos regulares em francês, os terminados por -er, em que há um apagamento do /R/ igual ao que ocorre no português coloquial e/ou não padrão com os infinitivos terminados em $-\mathrm{ar}^{10}$, tanto em variedades de menor quanto nas de maior prestígio sociolinguístico.

9 Observa-se que informal, na fala do sujeito, remete a registros coloquiais e/ou não padrão em variedades desprestigiadas do português.

10 Focou-se somente nas primeiras terminações - ar do português coloquial e/ou não padrão, embora o apagamento do /R/ de infinitivos possa ocorrer em todas as terminações nesta língua. Procedeu-se assim, porque não há uma equivalência biunívoca de apagamento do /R/ final de infinitivos nas demais terminações do francês padrão. 
Partindo-se dos exemplos 1, 2, e 3, que se expõem no Quadro 4, procedeu-se à leitura da frase Protéger l'environnement c'est préserver l'avenir de l'homme, contendo vocábulos no o contexto estudado, a saber: protéger e préserver. Ao realizarem a leitura os sujeitos fizeram os seguintes depoimentos, materializados em $3 \mathrm{a}$, frente à pergunta da professora-pesquisadora - Como ficam as palavras terminadas em "ER"?

3a: Sujeito 3 e Sujeito 2, concomitantemente: - [proteze] e [prezerve]

Professora: - Por que [proteze] e [prezerve]?

Sujeito 2: - Porque o /R/ do -er sai.

A leitura de vocábulos com a terminação - er de infinitivos regulares em atividades subsequentes, como o caso de manger, nas frases - nous mangeons tous les trois à la table de la salle à manger e il nous regarde manger $[\ldots]^{11}$, seguiu com o direcionamento, por parte da professora-pesquisadora, para o descompasso entre fala e escrita, de infinitivos regulares, que ocorrem em variedades prestigiadas ou não do português e que são padrão no francês, ou seja, a supressão do /R/ final de infinitivos regulares em registros falados nas duas variedades ponderadas. Em decorrência, os sujeitos, ao se depararem com palavras que continham o contexto supramencionado, monitoravam suas produções, adequando-as ao francês padrão e, de imediato, apagando o /R/ final do infinitivo regular.

(iv) Dado extraído da explicitação sobre estruturas /aw/ pronunciadas [o]

As atividades de intercomunicação linguística relativas à forma como o português na escrita e na oralidade em registro coloquial e/ou não padrão desprestigiado, bem como o francês padrão na oralidade e na escrita, procedem quanto à produção do ditongo / aw/ tomaram por base os exemplos apresentados no Quadro 5.

Quadro 5 - Exemplos concernentes a estruturas /aw/ pronunciadas [o] no português coloquial e/ou não padrão e no francês padrão

\begin{tabular}{|c|c|c|c|c|c|}
\hline \multicolumn{2}{|c|}{ Ocorrência } & $\begin{array}{l}\text { Português } \\
\text { Escrita }\end{array}$ & $\begin{array}{c}\text { Português Coloquial e/ou } \\
\text { não Padrão na oralidade } \\
\text { desprestigiada }\end{array}$ & $\begin{array}{l}\text { Francês } \\
\text { Escrita }\end{array}$ & $\begin{array}{l}\text { Francês } \\
\text { Padrão na } \\
\text { oralidade }\end{array}$ \\
\hline \multirow{3}{*}{$\begin{array}{l}\text { Estruturas /aw/ } \\
\text { pronunciadas [o] }\end{array}$} & 1. & Aumentar & [omẽta] & Augmenter & [ogmãte] \\
\hline & 2. & Autoridade & [otoridad3I] & Autorité & [otวrite] \\
\hline & 3. & Austeridade & [osteridadzI] $^{12}$ & Austérité & [ostesite] \\
\hline
\end{tabular}

Fonte: Elaboração própria.

\footnotetext{
11 Fragmento do texto de Marguerite Dumas - "Photo de Famille", referenciado na subseção (ii).

12 Exemplo observado, recentemente, em uma rede social.
} 
Tendo como suporte os exemplos ilustrados no Quadro 5, foi realizada, por intermédio da leitura da frase il est au chômage ${ }^{13}$, a atividade de intercomunicação. Foi frisado o fato de que /aw/ em au chômage se pronuncia semelhantemente a [otoridadzI] para "autoridade" nos dialetos de menor prestígio do português.

Quando instados a completarem com os verbos être e avoir, em frases semelhantes a Il ............mal au dos ${ }^{14}$. Ao ler a frase $I l$ a mal au dos, um dos sujeitos fez o comentário em $4 a$.

4a: Sujeito 1: - Quando cheguei no "au” fiquei entre [e] ou [o], não lembrava mais se era-ai ou-au que se pronunciava [o], aí me lembrei de [o]toridade para [aw] toridade e falei [o].

No momento da produção da frase Sur le balcon, il y a .....cage avec.....oiseau, houve uma hesitação quando da leitura do final da palavra oiseau, conforme se materializa em $4 b$.

4b: Sujeito 1: Sur le balcon, il a un [wa].....

Professora: Como vais ler o final desta palavra?

Sujeito 3: porque tem-au [o]toridade.

Professora: Então?

Sujeito 3: [wazo]

Os depoimentos expressos em $4 \mathrm{a}$ e $4 \mathrm{~b}$ sugerem que a aproximação entre as produções no francês padrão àquelas do português coloquial e/ou não padrão em variedades de menor prestígio sociolinguístico, auxiliaram os alunos na proficiência de expressões que exibiam alvos com contextos idênticos na LE, servindo, assim, de apoio à hora de lançar mão de suas hipóteses na produção exata do ditongo /aw/ na língua francesa.

Importante aludir, para que sejam entendidos os fenômenos de variação nas línguas estudadas, que processos de vocalização, tais como ocorre em /aw/ são registrados no francês desde o século XVII e, portanto, consolidados e tidos como padrão, já no português ainda constituem regra variável e, em dialetos de menor prestígio sociolinguístico (DOGLIANI, 2008a).

(v) Dado extraído da explicitação sobre apagamento final de substantivos terminados por /eN/

13 Disponível em: http://ayudafrances.blogspot.com/2014/01/conversacion-en-frances-sobre-la-familia.html. Acesso em: 23 mai. 2019.

14 Disponível em: https://www.professeurphifix.net/orthographe_impression/ortho_est_et_ai_es.pdf. Acesso em: 23 mai. 2019. 
Exemplos relativos à forma como o português na escrita e o português coloquial e/ou não padrão, tanto em variedades desprestigiadas quanto nas prestigiadas, e o francês padrão na oralidade e na escrita, procedem quanto ao apagamento final de nomes terminados por /eN/ seguem no Quadro 6.

Quadro 6 - Exemplos concernentes ao apagamento final de substantivos terminados por /eN/" no português coloquial e/ou não padrão e no francês padrão.

\begin{tabular}{|c|c|c|c|c|c|}
\hline \multicolumn{2}{|c|}{ Ocorrência } & $\begin{array}{c}\text { Português } \\
\text { Escrita }\end{array}$ & $\begin{array}{l}\text { Português Coloquial } \\
\text { e/ou não padrão na } \\
\text { oralidade prestigiada/ } \\
\text { desprestigiada }\end{array}$ & $\begin{array}{c}\text { Francês } \\
\text { Escrita }\end{array}$ & $\begin{array}{l}\text { Francês } \\
\text { Padrão na } \\
\text { oralidade }\end{array}$ \\
\hline \multirow{3}{*}{$\begin{array}{l}\text { Substantivos } \\
\text { terminados } \\
\text { por /eN/ }\end{array}$} & 1. & Garagem & [garazj] & Garage & [gаваз] \\
\hline & 2. & Viagem & [viazj] & Voyage & [vwajaz] \\
\hline & 3. & Passagem & [pasazj] & Passage & [pasaz] \\
\hline
\end{tabular}

Fonte: Elaboração própria.

A explicitação da desnasalização das vogais átonas finais, que no português é um indicador de variedades sociais, diastráticas, mas também, ocorre em registros da variedade padrão, porém com maior frequência em registros não monitorados, BortoniRicardo (2005), tomou por base a palavra image em francês, pronunciada [imaz].

Ao se proceder à leitura da frase ${ }^{15}$ - Protéger l'environnement c'est préserver l'avenir de l'homme, um dos sujeitos fez a seguinte observação, apresentada em 5a, diante da produção da palavra homme.

5a: Sujeito 2: - O homem é o do [כm], tipo [pasazj], [viazj] tira o -m. Aí fica [วm], como no português?

Na continuidade do estudo, quando os discentes, ao se depararem com as palavras village e carnage procederam às observações, relatadas em $5 \mathrm{~b}$.

5b: Sujeito 3: -Tout est sage dans le [vila]...[3].

Sujeito 2:- [vilaz], [gава3]

Professora: -Isso! pela mesma regra!

Sujeito 2: -Plus de [ваз], plus de [kaьnaz].

Professora: -Vocês tiveram algum problema para ler [kasnaz]?

Sujeito1, Sujeito 2 e sujeito 3, concomitantemente: Não!

Em 5a e 5b é possível observar que a atividade de intercomunicação parece ter sido útil aos sujeitos, servido de apoio quando da produção de substantivos abrangendo o

15 Mesmo exercício trabalhado para o apagamento de /R/ em infinitivos regulares. 
contexto estudado, ou seja, eles conseguiram criar um elo entre o português coloquial e/ou não padrão e o francês padrão, procedendo com o apagamento do $/ \mathrm{m} / \mathrm{final} \mathrm{em}$ nomes contendo os alvos referidos na LE em questão.

(vi) Dado extraído da explicitação sobre a regularidade do paradigma verbal no presente do indicativo e da obrigatoriedade do sujeito

Exemplos concernentes à forma como o português na escrita e na coloquialidade e/ou não padrão, em variedades desprestigiadas, e o francês padrão na escrita e na oralidade, procedem quanto ao paradigma verbal no presente do indicativo, apresentamse no Quadro 7.

Quadro 7 - Exemplos concernentes à regularidade do paradigma verbal no presente do indicativo no português coloquial e/ou não padrão e no francês padrão

\begin{tabular}{|c|c|c|c|c|}
\hline $\begin{array}{l}\text { Ocorrência } \\
\text { Fenômeno }\end{array}$ & $\begin{array}{l}\text { Português } \\
\text { Escrita }\end{array}$ & $\begin{array}{c}\text { Português Coloquial } \\
\text { e/ou não Padrão } \\
\text { Oralidade Prestigiada }\end{array}$ & $\begin{array}{c}\text { Francês } \\
\text { Escrita }\end{array}$ & $\begin{array}{l}\text { Francês } \\
\text { Padrão } \\
\text { Oralidade }\end{array}$ \\
\hline $\begin{array}{l}\text { Regularidade } \\
\text { do paradigma } \\
\text { verbal }\end{array}$ & $\begin{array}{l}\text { Eu falo } \\
\text { tu falas } \\
\text { ele(a)/você fala } \\
\text { nós falamos } \\
\text { vós falais } \\
\text { vocês falam } \\
\text { eles(as)falam }\end{array}$ & $\begin{array}{l}\text { eu falo } \\
\text { [falu] } \\
\text { Tu/ele(a)/você/nós/ a } \\
\text { gente/vocês/eles(as) } \\
\text { fala } \\
\text { [fale] }\end{array}$ & $\begin{array}{l}\text { je parle } \\
\text { tu parles } \\
\text { il/elle parle } \\
\text { nous parlons } \\
\text { vous parlez } \\
\text { ils/elles parlent }\end{array}$ & $\begin{array}{l}\text { je,/tu/il/ elle/ } \\
\text { ils/elles/on } \\
\text { [равl] } \\
\text { nous } \\
\text { [равlõ] } \\
\text { vous } \\
\text { [равle] }\end{array}$ \\
\hline
\end{tabular}

Fonte: Elaboração própria.

O Quadro 7 reproduz por intermédio dos verbos falar e parler a explicitação realizada na aula de FLE, relativa à morfologia verbal que registra uma diminuição da flexões, conformando-se no português como regra variável e no francês em uma regra categórica, resquício da forma como a palavra era pronunciada em outro momento da evolução linguística. Isso porque a ortografia do francês, consolidada por volta do século XVIII, por apresentar maior descompasso à do português na correlação entre grafemas e fonemas, permite a visualização da forma como as palavras eram produzidas em estágios anteriores à língua, remetendo ao latim. Assim, em francês, os verbos se escrevem com as desinências, resquícios da época em que se diziam assim (DOGLIANI, 2008a; ESCUDÉ; CALVO DEL OLMO, 2019).

Isso posto, e com base, mormente nos exemplos exibidos pelo Quadro 7, aos alunos foi facultada a tarefa de conjugar no presente do indicativo os verbos manger $\mathrm{e}$ comer, respectivamente no francês padrão e no português coloquial e/ou não padrão. Os resultados da atividade se concretizam em 6a, a seguir. 
6a: Professora: - Vamos pensar nos verbos comer e manger. Primeiro vamos conjugar o verbo "comer" no português coloquial?

Sujeito1, Sujeito 2 e Sujeito 3, concomitantemente: - eu [komu], tu [komj], ele [komj], nóis [komj], eles [komj].

Professora: - Vamos pensar em manger no francês padrão?

Sujeito 1: - je [mã3], tu [mã3].

Sujeito 3: - il [mã3].

Sujeito 2: - nous [mã Z̃̃].

Sujeito 1: - vous [mã $3 e]$.

Professora: - Entenderam? Tout le monde [mã3], sauf nous et vous!

A intercomunicação realizada abre caminho para a explicação a respeito da obrigatoriedade do sujeito nas produções em francês. O raciocínio se debruça sobre o fato de se a neutralização da desinência verbal acontecer, como nos casos de falar nas produções coloquiais e/ou não padrão do português, há certa opacidade em relação a quem faz a ação, por isso nas falas coloquiais e/ou não padrão é comum se marcar o sujeito. Tal raciocínio, se estendido às produções padrões do francês tem a mesma validade. Em francês a marcação do sujeito é obrigatória. Segundo Dogliani (2008a) a identificação da pessoa do verbo torna-se opaca, dependendo da explicitação por intermédio dos pronomes pertinentes. Em $6 \mathrm{~b}$ aparecem os depoimentos advindos de tais afirmações.

6b: Professora: Se temos esta opacidade na terminação verbal é preciso marcar o sujeito, até para saber quem é a pessoa que fala.

Sujeito 2: Por isso que a senhora deu ênfase na hora de botar as características? (se referindo a um texto produzido para caracterizar as personagens de um filme exibido precedentemente).

Professora: Por isso... E o que eu disse?

Sujeito 2: Que tinha que botar o "il".

Professora: Exatamente! Que tinha que marcar o sujeito.

As estratégias de produção dos sujeitos, ao confrontarem alvos relativos à regularidade do paradigma verbal e à obrigatoriedade do sujeito, nas duas línguas e em suas variedades distintas, expostos em $6 \mathrm{a}$ e $6 \mathrm{~b}$, consubstanciam a possibilidade de trabalhar em aulas de FLE, a vertente da reflexão entre o português coloquial e/ou não padrão e o francês padrão, ao demonstrar que os alunos conseguiram fazer uso pragmático de contextos idênticos à variação do português, transpondo-os e deslocandoos às produções adequadas na LE. Afirmação que repercute em Martins (2014), ao definir intercompreensão, por meio das palavras de Capucho (2004 apud MARTINS, 2014), defendendo a capacidade de co-construção de sentido entre línguas diferentes e o uso pragmático dessa capacidade em situações comunicativas concretas. 
Finalmente, como última consideração, ressalta-se que chamar atenção a processos análogos nas duas línguas em contato neste estudo, em especial àqueles ocorridos no francês, demonstrando que esta língua, por estar mais evoluída que a LM: o português, porque se distancia mais do latim, língua da qual ambas descendem, apresenta fenômenos cristalizados, há muito tempo, porém ainda em variação no português, possibilitará o entendimento, segundo o qual algumas formas presentes nos registros falados de muitos, poderão no futuro ser a única alternativa no português, semelhantemente ao ocorrido, outrora, com a língua francesa, na qual esses registros estavam em variação e, atualmente, encontram-se consolidados. Atividades desse tipo auxiliam e contribuem para a sensibilização à diversidade linguística (MOZZILLO, 2006; DOGLIANI, 2008b; ESCUDÉ; CALVO DEL OLMO, 2019).

\section{Conclusão}

Neste artigo, arguiu-se em favor da ideia de que atividades que instigam a intercomunicação entre produções, que se assemelham no português coloquial e/ou não padrão e no francês padrão, são capazes de gerar melhor proficiência na LE.

As atividades de integração linguística foram eficazes, ao servirem de suporte para as adequações entre as variedades nas línguas estudadas. Esse achado demonstra o papel importante que a LM exerce nas salas de aula de LE, dialogando com as palavras de Moore (2008, p. 94-95), que corroboram a noção segundo a qual

[...] a questão da alternância racional das línguas está baseada na execução de atividades suscetíveis de favorecer a passagem para a conceituação de saberes que o aluno já tem, de tirá-los da obscuridade, tornando-os objetos de reflexão e, eventualmente, a aprender a apoiar-se neles para a apreensão de outros contextos linguísticos.

Palavras que repercutem nos depoimentos dos sujeitos frente à questão da professora/pesquisadora: Estas comparações, entre o português coloquial e o francês padrão, estão ajudando vocês?

Sujeito 2: $\operatorname{Sim}$

Professora: Em que sentido?

Sujeito 1:-Na comunicação

Sujeito 2: É que a gente já tá habitando, não é habitando (querendo dizer habituado), a gente já tá com eles já, a gente fala assim.

Sujeito 1:-É muito mais fácil a gente trazer uma coisa que a gente ouve no dia a dia e colocar em prática numa outra língua... é muito mais fácil. 
Por fim, não se pode deixar de fazer referência à contribuição deste estudo para com as discussões que envolvem práticas linguísticas intercomunicativas. Ao adquirir suporte para intercomunicar as duas línguas alvo e assim poder desenvolver as competências oral e escrita em FLE, bem como produzir estruturas de acordo com o francês padrão, também foi oportunizada ao aprendiz a possibilidade de, por extensão compreender que a variação no português é algo que contribui fortemente à diversidade linguística e à reflexão sobre a linguagem como um todo. As conexões linguísticas aqui demonstradas vão ao encontro de projetos que defendem a interação, tal como preconiza Candelier (2016, p. 108) ao afirmar que, "ensinar uma língua significa levar em consideração todas as habilidades linguísticas déjà-là, a fim de ajudar os alunos a conectar o novo idioma a outros já existentes".

ROMBALDI, C.; MOZZILLO, I. Intercommunication of colloquial and/or non-standard Portuguese and standard French in a French as a foreign language class. Alfa, São Paulo, v.65, 2021.

- ABSTRACT: In this article, aspects of variation in Portuguese are related to those crystallized by French grammar, to establish intercommunications between productions that are similar in colloquial and/or non-standard Portuguese and standard French, based on the hypothesis that intercommunicative activities of explicitness between such particularities in both languages can improve FL proficiency. This hypothesis is based on the work of Miranda de Paulo (2017), Candelier (2016), and Bagno (1999). The methodology comprises expository and dialogical classes, which focus on stimulating students to contrast and interrelate activities that contextualize words or expressions in standard French that are organized in a similar way to variation in Portuguese. The results show that the subjects, besides contrasting the two varieties in the languages in the study, also transposed structures from one variety to the other, adapting them to standard French.

- KEYWORDS: integrated didactics; Portuguese as mother tongue; French as a foreign language; standard French; colloquial and/or non-standard Portuguese.

\section{REFERÊNCIAS}

BADY, J.; GREAVES, I.; PETETIN, A. Grammaire 350 exercíces Níveau Débutant. Paris: Hachete, 1996.

BAGNO, M. Preconceito linguístico: o que é, como se faz. São Paulo: Loyola, 1999. BORTONI-RICARDO, S. M. Manual de sociolinguística. São Paulo: Contexto, 2014. BORTONI-RICARDO, S. M. Nós cheguemu na escola, e agora?: sociolinguística \& educação. São Paulo: Parábola, 2005. 
BORTONI-RICARDO, S. M. Educação em língua materna: a sociolinguística em sala de aula. São Paulo: Parábola, 2004.

CANDELIER, M. Activités métalinguistiques pour une didactique intégrée des langues. Le Français aujourd'hui, Paris, n. 192, p. 107-116, 2016. Disponível em: https:/www. cairn.info/revue-le-francais-aujourd-hui-2016-1-page-107.htm. Acesso em 21 abr. 2020.

CASTELLOTTI, V. L'hétérogénéité, fondement de l'éducation linguistique? vers des perspectives alterdidactiques. GLOTTOPOL, Rouen, n. 23, p.188-225, jan. 2014. Disponível em: http://glottopol.univ-rouen.fr/telecharger/numero_23/ gp123_09castellotti.pdf. Acesso em 21 abr. 2020.

CASTELLOTTI, V. La langue maternelle en classe de langue étrangère. Paris: Clé International, 2001.

CHISS, J. L. La Didactique du Français entre conceptualisation et contextualisation. In: BARROS, M.; BARBOSA, M.; ROCHEBOIS, C. Recherche en didactique de langues étrangères: thème majeurs: Pesquisas em didática de línguas estrangeiras: Grandes temas. Belo Horizonte: Faculdade de Letras/UFGM, 2013. p.13-26.

COUTO, H. Línguística, ecologia e ecolinguística: contato de Línguas. São Paulo: Contexto, 2009.

DAHLET, P. Línguas distintas e Línguagem mútua: Língua Materna Língua Estrangeira na Escola. Belo Horizonte: Autêntica, 2008.

DEGACHE, C.; GARBARINO, S. Itinéraires pédagogiques de l'alternance des langues: l'intercompréhension. Grenoble: ELLUG, 2017. (Collection Didaskein).

DOGLIANI, E. Sensibilização à diversidade linguística em L1, através do ensino de L2 e da Didática Integrada das línguas. In: KURTZ, S. C. dos S.; MOZZILLO, I. Cultura e diversidade na sala de aula de língua estrangeira. Pelotas: Ed. da UFPel, 2008a. p. 109-122.

DOGLIANI, E. Crenças comuns e divergentes entre a sala de aula de Língua estrangeira e a sala de aula de língua materna. In: KURTZ, S. C. dos S.; MOZZILLO, I. Cultura e diversidade na sala de aula de língua estrangeira. Pelotas: Ed. da UFPel, 2008b. p. 123-130.

DOGLIANI, E. (org.). Didática integrada das línguas. Belo Horizonte: FALE/UFMG, 2008c. Disponível em: http://www.letras.ufmg.br/padrao_cms/documentos/eventos/ vivavoz/didaticaintegrada-site.pdf. Acesso em: 28 mar. 2019.

ESCUDÉ, P.; CALVO Del OLMO, F. Intercompreensão: a chave para as línguas. São Paulo: Parábola, 2019.

MARTINS, S. A. A intercompreensão de línguas românicas: proposta propulsora de uma educação plurilíngue. MOARA: Revista Eletrônica do Programa de Pós-Graduação 
em Letras, Belém, n.42, p.117-126, jul./dez. 2014. Disponível em: https://periodicos. ufpa.br/index.php/moara/article/view/2059. Acesso em 23 dez. 2019.

MIRANDA de PAULO, L. Novos tempos, novas didáticas: caminhos para a (trans) formação de professores via intercompreensão no Brasil / New times, new didactics: ways to train teachers by intercomprehension approach in Brazil. Revistas Letras Raras, Campina Grande, v. 6, n. 3, 2017. Disponível em: https://www.researchgate. net/publication/331638324_Novos_tempos_novas_didaticas_caminhos_para_a transformacao_de_professores_via_intercompreensao_no_Brasil_New_times_new_ didactics_ways_to_train_teachers_by_intercomprehension_approach_in_Brazil. Acesso em: 21 abr. 2020.

MOORE, D. Uma didática de alternância para aprender melhor?: Língua Materna Língua Estrangeira na Escola. Belo Horizonte: Autêntica, 2008.

MOZZILLO, I. O contato português-francês na sala de aula: a questão do prestígio e do desprestígio de variedades linguísticas. Caderno de Letras, Pelotas, v. 24, n. 12, p. 40-44, 2006.

OLIVEIRA, L. C. Didática integrada: o ensino de língua portuguesa como L2. In: UNIVERSIDADE FEDERAL DE MINAS GERAIS. Didática Integrada das Línguas. Belo Horizonte: FALE/UFMG, 2008. p. 15-26.

Recebido em 3 de julho de 2020

Aprovado em 31 de março de 2021 